\title{
Article \\ E/D-Mode GaN Inverter on a 150-mm Si Wafer Based on p-GaN Gate E-Mode HEMT Technology
}

\author{
Li-Fang Jia ${ }^{1,2}$, Lian Zhang ${ }^{1,2}$, Jin-Ping Xiao ${ }^{3}$, Zhe Cheng ${ }^{1,2}$, De-Feng Lin ${ }^{1,2}$, Yu-Jie Ai ${ }^{1,4}$, Jin-Chao Zhao ${ }^{5}$ \\ and Yun Zhang ${ }^{1,2, *}$ \\ 1 Laboratory of Solid State Optoelectronics Information Technology, Institute of Semiconductors, CAS, \\ Beijing 100083, China; lfjia@semi.ac.cn (L.-F.J.); zhanglian07@semi.ac.cn (L.Z.); zhecheng@semi.ac.cn (Z.C.); \\ dflin@semi.ac.cn (D.-F.L.); aiyujie@semi.ac.cn (Y.-J.A.) \\ 2 Center of Materials Science and Optoelectronics Engineering, University of Chinese Academy of Sciences, \\ Beijing 100049, China \\ 3 Silan Integrated Circuit Co., Ltd., Hangzhou 310018, China; xiaojinping@silanic.com.cn \\ 4 Lishui Zhongke Semiconductor Material Co., Ltd., Lishui 323000, China \\ 5 Xiamen Silan Advanced Compound Semiconductor Co., Ltd., Xiamen 361026, China; \\ zhaojinchao@silanled.com \\ * Correspondence: yzhang34@semi.ac.cn
}

check for updates

Citation: Jia, L.-F.; Zhang, L.; Xiao, J.-P.; Cheng, Z.; Lin, D.-F.; Ai, Y.-J.; Zhao, J.-C.; Zhang, Y. E/D-Mode GaN Inverter on a $150-\mathrm{mm}$ Si Wafer Based on p-GaN Gate E-Mode HEMT Technology. Micromachines 2021, 12, 617. https://doi.org/10.3390/ mi12060617

Academic Editors: Shyh-Chiang Shen Chien-Chung Lin and Chao-Hsin Wu

Received: 25 April 2021

Accepted: 24 May 2021

Published: 27 May 2021

Publisher's Note: MDPI stays neutral with regard to jurisdictional claims in published maps and institutional affiliations.

Copyright: (c) 2021 by the authors. Licensee MDPI, Basel, Switzerland. This article is an open access article distributed under the terms and conditions of the Creative Commons Attribution (CC BY) license (https:/ / creativecommons.org/licenses/by/ $4.0 /)$.

\begin{abstract}
AlGaN/GaN E/D-mode GaN inverters are successfully fabricated on a 150-mm Si wafer. P-GaN gate technology is applied to be compatible with the commercial E-mode GaN power device technology platform and a systematic study of E/D-mode GaN inverters has been conducted with detail. The key electrical characters have been analyzed from room temperature (RT) to $200{ }^{\circ} \mathrm{C}$. Small variations of the inverters are observed at different temperatures. The logic swing voltage of $2.91 \mathrm{~V}$ and $2.89 \mathrm{~V}$ are observed at RT and $200{ }^{\circ} \mathrm{C}$ at a supply voltage of $3 \mathrm{~V}$. Correspondingly, low/high input noise margins of $0.78 \mathrm{~V} / 1.67 \mathrm{~V}$ and $0.68 \mathrm{~V} / 1.72 \mathrm{~V}$ are observed at RT and $200{ }^{\circ} \mathrm{C}$. The inverters also demonstrate small rising edge time of the output signal. The results show great potential for GaN smart power integrated circuit (IC) application.
\end{abstract}

Keywords: AlGaN/GaN; E-mode; D-mode; p-GaN; inverter; monolithic integration; small variations

\section{Introduction}

GaN-based power devices are promising for high temperature, high frequency and high-power applications owing to their high two-dimensional electron gas (2DEG) mobility and high breakdown voltage [1-3]. However, mostly, the logic controller and the driver modules for $\mathrm{GaN}$ power devices are still implemented with $\mathrm{Si}$ integrated circuits (ICs) $[4,5]$. As we know, the larger parasitic inductance by integration could lower the performance of the GaN device under high-frequency and increase the cost. Hence, it is very important to develop GaN-based ICs to fully exploit the advantages of GaN-based ICs. GaN complementary metal-oxide-semiconductor (CMOS) logic is challenging because it is hard to get high-performance p-channel GaN. The direct-coupled field-effect transistor (FET) logic (DCFL) ICs with monolithically integrated E/D-mode n-channel devices offer a straight-forward and convenient approach to implementing GaN digital ICs.

Some methods based on D-mode GaN technology, for example, gate recess process [6-8] and $\mathrm{F}$ ion implantation $[9,10]$ have been proposed to realize E-mode $\mathrm{GaN}$ high-electronmobility transistors (HEMTs) and E/D-mode inverters. These works are either based on Schottky-gate HEMTs or MIS (metal-insulated-semiconductor)-gate HEMTs, and neither of them have been adopted in commercial GaN power devices, due to small gate swing in Schottky-gate HEMTs and gate-dielectric reliability concerns in MIS-HEMTs. The p-GaN gate technology has been approved to decrease the gate leakage and increase the gate voltage swing. It is already commercially available for its excellent characteristics and stability $[2,11,12]$. Some GaN ICs based on the p-GaN gate technology platform $[13,14]$ 
have been reported in recent years; however, the systematic study and research of the $\mathrm{E} / \mathrm{D}$-mode $\mathrm{GaN}$ inverters based on $\mathrm{p}-\mathrm{GaN}$ gate technology is not reported until now.

In this paper, monolithic integration of $\mathrm{E} / \mathrm{D}$-mode GaN inverters are demonstrated based on a p-GaN gate technology platform and the direct current (DC) and transient characteristics are studied. A very distinct property of $\mathrm{GaN}$ compared to silicon is its high temperature operation, and the characteristics of the GaN inverters operating at high temperatures are also studied in details. The inverters show large input voltage swing and wide noise margin from room temperature to $200^{\circ} \mathrm{C}$.

\section{Materials and Methods}

The schematic and the image of the E/D-mode GaN inverter are demonstrated in Figure 1.

(a)

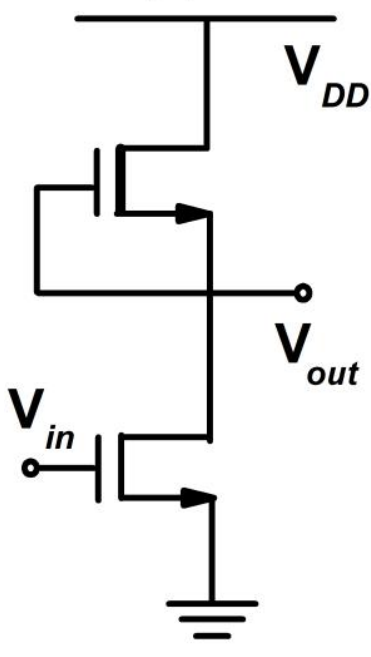

(b)

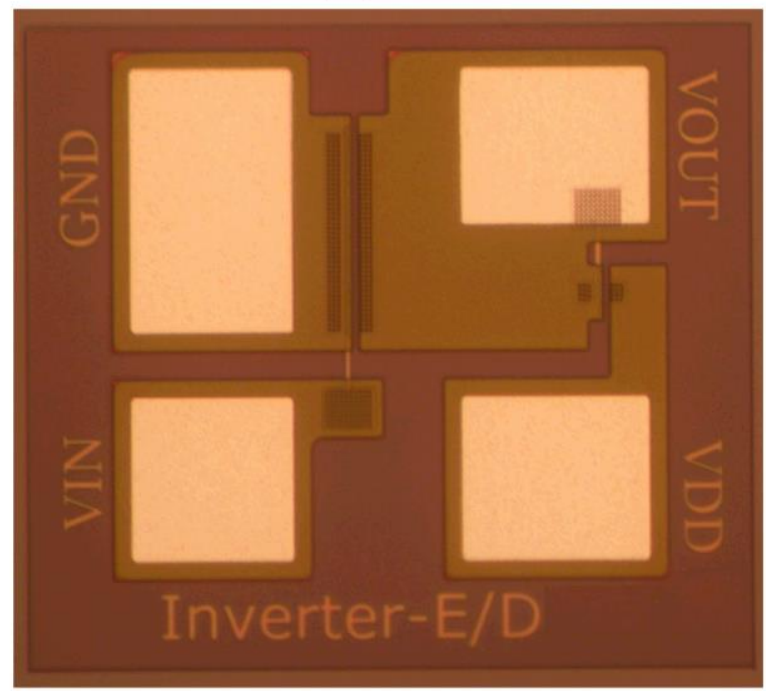

Figure 1. (a) A typical circuit schematic of the E/D-mode GaN inverter and (b) top view of the fabricated E/D-mode inverter.

The key processing steps of the E/D-mode GaN monolithic integration technology are shown in Figure 2. The E/D-mode GaN inverters were fabricated on p-GaN/AlGaN/GaN epitaxial layer on a 150-mm Si substrate. The epitaxial layer was grown through metal organic chemical vapor deposition (MOCVD) and included about 200-nm AlN nucleating layer, about 3.5- $\mu \mathrm{m}$ high resistive buffer layer, about 300-nm un-doped GaN channel layer, and about $18-\mathrm{nm} \mathrm{Al}_{0.13} \mathrm{Ga}_{0.87} \mathrm{~N}$ barrier layer. Then, about 90-nm p-type $\mathrm{GaN}$ layer was grown and the $\mathrm{Mg}$ concentration was about $1 \times 10^{19} \mathrm{~cm}^{-3}$. Finally, it was annealed within the MOCVD chamber at $650{ }^{\circ} \mathrm{C}$ for $15 \mathrm{~min}$.

The E-mode and D-mode GaN HEMT were fabricated in the same batch. For E/Dmode GaN devices and inverters' fabrication, the mesa region was formed with $\mathrm{N}$ ion implantation. Then $\mathrm{p}-\mathrm{GaN}$ etching was carried out by $\mathrm{BCl}_{3} / \mathrm{Cl}_{2}$-based inductive couple plasma (ICP) with low DC power for low damage and high etching selectivity with $\mathrm{Al}_{0.13} \mathrm{Ga}_{0.87} \mathrm{~N}$. In this step, the p-GaN was totally etched for D-mode GaN HEMT and was partly left as p-GaN gate for the E-mode GaN HEMT. Then, plasma-free $\mathrm{SiO}_{2}$ chemical vapor deposition (CVD) was deposited as the first passivation. Au-free ohmic contact metal stack $\mathrm{Ti} / \mathrm{Al} / \mathrm{Ti} / \mathrm{TiN}$ was sputtered after $\mathrm{SiO}_{2}$ etching. The ohmic contact metal was patterned by $\mathrm{BCl}_{3} / \mathrm{Cl}_{2}$ dry etching process. After that, the sample was annealed at $850{ }^{\circ} \mathrm{C}$ for $30 \mathrm{~s}$ in $\mathrm{N}_{2}$ ambient and the ohmic contact resistance was $0.6 \Omega \cdot \mathrm{mm}$. After removing $\mathrm{SiO}_{2}$ by $\mathrm{SF}_{6}$ plasma etching, about 20-nm atom layer deposition (ALD) $\mathrm{Al}_{2} \mathrm{O}_{3}$ was deposited at $200{ }^{\circ} \mathrm{C}$ as the gate dielectric for the D-mode device. Then, TiN was deposited and defined by ICP etching as the gate metal for D-mode GaN HEMT. For the E-mode GaN 
device, the gate window was opened by etching $\mathrm{Al}_{2} \mathrm{O}_{3}$ and $\mathrm{SiO}_{2}$ with low $\mathrm{DC}$ bias and $\mathrm{Ti} / \mathrm{Al}$ gate metal was deposited and defined by ICP etching. Lastly, about 100-nm plasma enhancement chemical vapor deposition (PECVD) was deposited as the last passivation, and then the pad contact was opened by wet etching. D-mode and E-mode have a gate length of $1.5-\mu \mathrm{m}$ and $1.8-\mu \mathrm{m}$, respectively. Both the D-mode and E-mode have the same gate width of $100-\mu \mathrm{m}$, gate-to-source distance of $1.5-\mu \mathrm{m}$, and gate-to-drain distance of $5-\mu \mathrm{m}$. $I-V$ measurement was performed using Aglient B1500 semiconductor device analyzer.
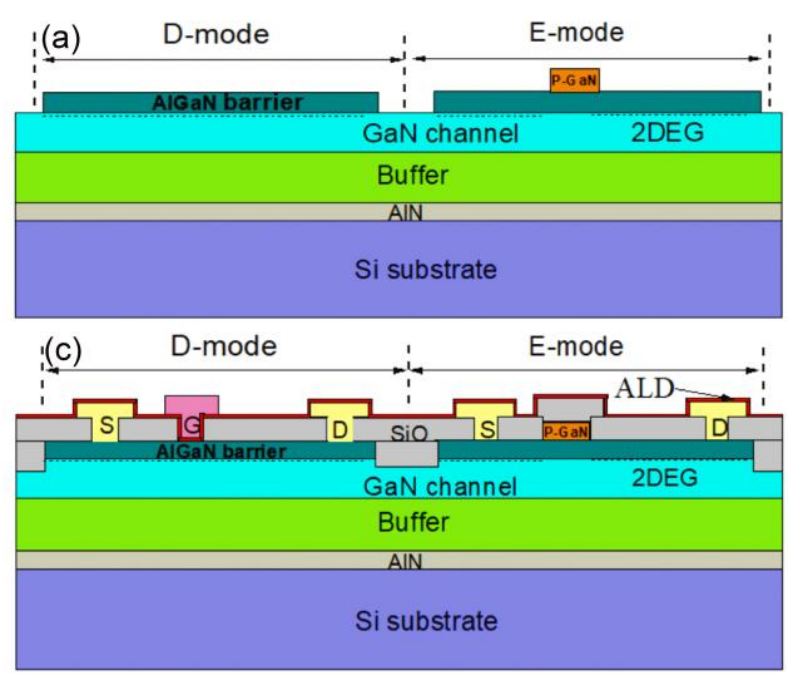
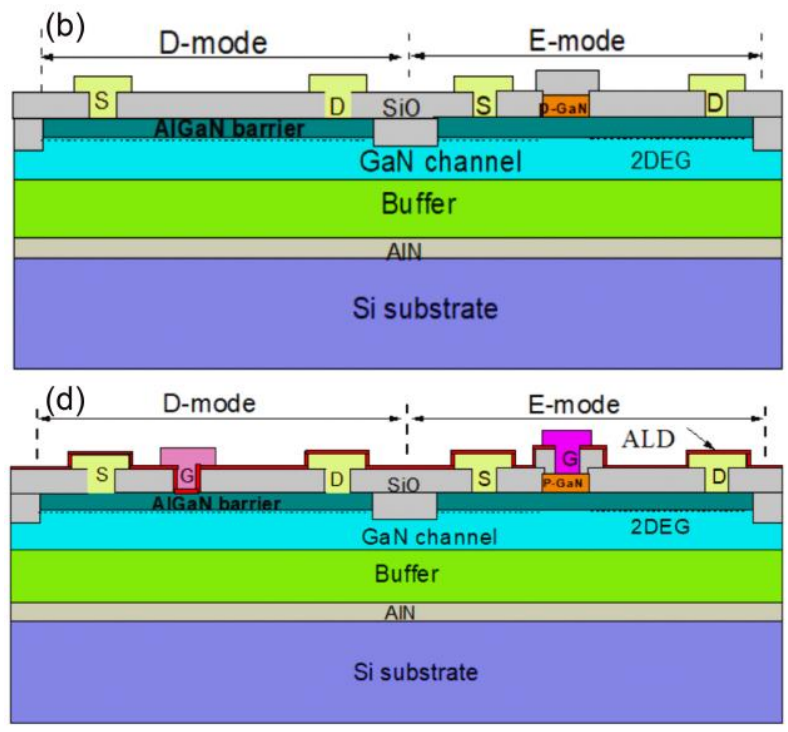

Figure 2. Schematic cross-section of (a) after p-GaN etching, (b) after source and drain formation and (c) after gate metal etching of the D-mode GaN high-electron-mobility transistor (HEMT) device and (d) after the gate metal etching of the E-mode GaN HEMT device.

\section{Results}

\subsection{E/D-Mode GaN HEMTs}

The DC output and transfer characteristics of E/D-mode HEMTs fabricated on the same wafer are plotted in Figures 3 and 4. At room temperature (RT), the threshold voltage $\mathrm{V}_{\mathrm{TH}}$ is $+1.2 \mathrm{~V}$ and $-14.5 \mathrm{~V}$ for E-mode and D-mode GaN HEMT by linear extraction method, respectively. The maximum drain current density $\mathrm{I}_{\mathrm{DS} \text {, max }}$ is $312 \mathrm{~mA} / \mathrm{mm}$ $\left(\right.$ at $\mathrm{V}_{\mathrm{GS}}=7 \mathrm{~V}$ ) for the E-mode HEMT and $378 \mathrm{~mA} / \mathrm{mm}\left(\right.$ at $\mathrm{V}_{\mathrm{GS}}=2 \mathrm{~V}$ ) for the D-mode HEMT. The maximum current density for D-mode HEMT is lower than normal devices should be, as a result of the lower Al concentration of the AlGaN barrier layer. As the limitation of the probe, the highest test temperature is $200{ }^{\circ} \mathrm{C}$ in the paper. At $200{ }^{\circ} \mathrm{C}$, the $\mathrm{V}_{\mathrm{Th}}$ of the E-mode HEMT is $1.1 \mathrm{~V}$ and with $0.1 \mathrm{~V}$ drift. The E-mode HEMT exhibits a maximum current density of $152 \mathrm{~mA} / \mathrm{mm}$ at $200{ }^{\circ} \mathrm{C}$, which is about $52 \%$ lower than that at room temperature. The lower maximum current density at high temperature may be due to the low mobility of the 2DEG, caused by impurity scattering $[13,14]$. For the D-mode HEMT the $V_{\mathrm{TH}}$ increases to $-12.4 \mathrm{~V}$, with $+2.1 \mathrm{~V}$ drifting at $200{ }^{\circ} \mathrm{C}$. The larger $\mathrm{V}_{\mathrm{TH}}$ shifting for the D-mode HEMT at high temperature may be due to the fact that the 2DEG is captured by the interfaces of the gate metal $/ \mathrm{Al}_{2} \mathrm{O}_{3} / \mathrm{AlGaN}$ structure [15]. The maximum current density of the D-mode exhibits $64 \%$ lower and it is $179 \mathrm{~mA} / \mathrm{mm}$.

Figure 4 plots the gate leakage characteristics of the E-mode and D-mode HEMTs. Both of them can operate safely at $-6 \mathrm{~V} \sim+6 \mathrm{~V}$ at room temperature and $200{ }^{\circ} \mathrm{C}$. The off-state gate leakage current increases about two orders of magnitude with the increase of temperature for the E-mode HEMT. The D-mode HEMT shows much lower gate current leakage at the forward bias and this may due to the high insulation quality of $\mathrm{ALD} \mathrm{Al}_{2} \mathrm{O}_{3}$ layer. 

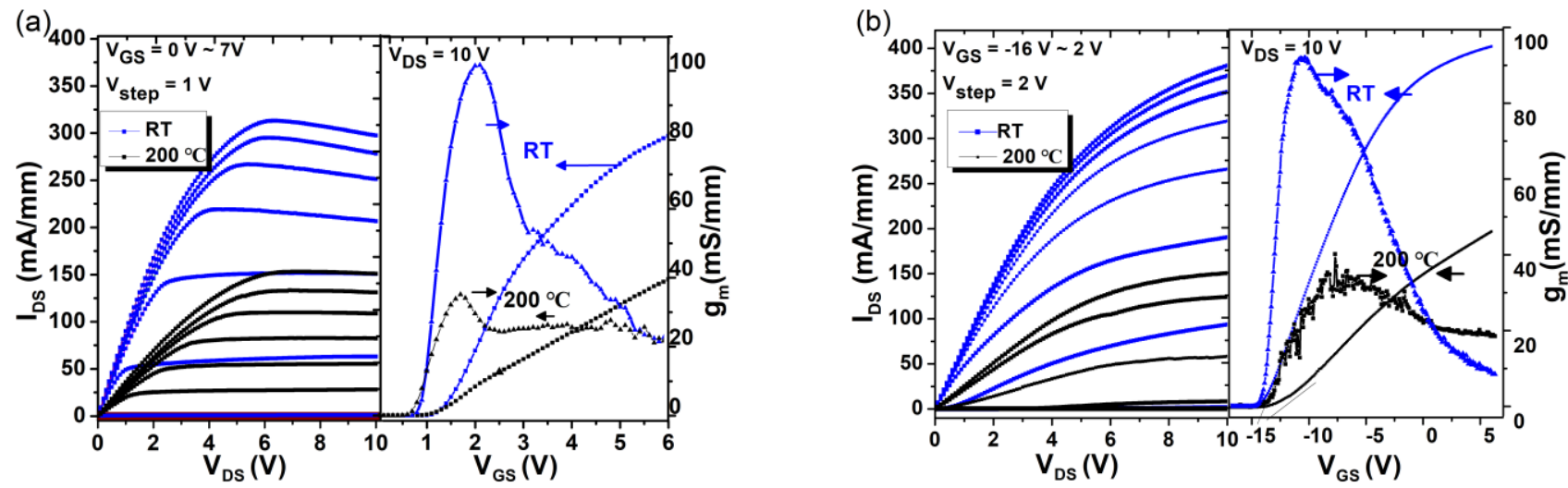

Figure 3. Direct current (DC) output and transfer characteristics for (a) E-mode GaN HEMT with $\mathrm{L}_{\mathrm{G}} / \mathrm{L}_{\mathrm{GS}} / \mathrm{L}_{\mathrm{GD}}=1.8 / 1 / 5-\mu \mathrm{m}$ and (b) D-mode GaN HEMT with $\mathrm{L}_{\mathrm{G}} / \mathrm{L}_{\mathrm{GS}} / \mathrm{L}_{\mathrm{GD}}=1.5 / 1 / 5-\mu \mathrm{m}$.

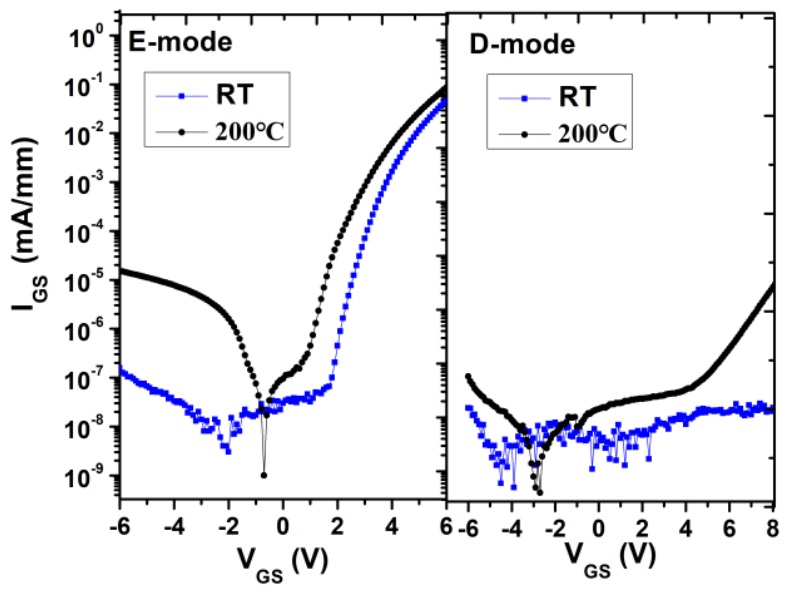

Figure 4. Gate leakage current for both E-mode and D-mode at room temperature and $200{ }^{\circ} \mathrm{C}$.

\section{2. $E / D G a N$ Inverters}

As shown in Figure 1a, the D-mode HEMT serves an active load and the E-mode HEMT serves as a driver of the inverter. In this paper, the gate-source-shorted D-mode HEMT is with a $W_{G} / L_{G}=(14-\mu \mathrm{m} / 1.5-\mu \mathrm{m})$, and different driver-to-load resistance ratio $\alpha=(W / L)_{E} /(W / L)_{D}$ is fabricated with different $(W / L)_{E}$. Figure 5 shows a typical E/D-mode $\mathrm{GaN}$ inverter with a driver/load ratio $\alpha=15$ and a supply voltage $\mathrm{V}_{\mathrm{DD}}=3 \mathrm{~V}$. The red curve is the same transfer curve with the axis interchanged and represents the input-output characteristics. The output high $\left(\mathrm{V}_{\mathrm{OH}}\right)$ and low $\left(\mathrm{V}_{\mathrm{OL}}\right)$ voltage of the inverter are $3.0 \mathrm{~V}$ and $0.09 \mathrm{~V}$, respectively, yielding a large voltage swing of $2.91 \mathrm{~V}(97 \%)$, close to the best values in the literature [10] with $\alpha=64$. The input logic low $\left(\mathrm{V}_{\mathrm{IL}}\right)$ and high $\left(\mathrm{V}_{\mathrm{IH}}\right)$ voltage level, extracted from the voltage unit gain points $\left(\mathrm{G}=d \mathrm{~V}_{\text {Out }} / d \mathrm{~V}_{\text {in }}=-1\right)$, are $0.87 \mathrm{~V}$ and $1.33 \mathrm{~V}$, respectively. The transition voltage region $\mathrm{V}_{\mathrm{TR}}$ (defined as $\mathrm{V}_{\mathrm{TR}}=\mathrm{V}_{\mathrm{IH}}-\mathrm{V}_{\mathrm{IL}}$ ) is $0.46 \mathrm{~V}$ (15\%), close to value as that in literature [10] with $\alpha=64$, showing the high performance of the logic inverter. The threshold of the inverter is $1.10 \mathrm{~V}\left(\mathrm{~V}_{\mathrm{TH}}\right.$,inverter, defined by $\mathrm{V}_{\text {out }}$ $\left.=\mathrm{V}_{\text {in }}\right)$. The logic low noise margin $\left(\mathrm{N}_{\mathrm{ML}}=\mathrm{V}_{\mathrm{IL}}-V_{\mathrm{OL}}\right)$ is $0.78 \mathrm{~V}$ and the high noise margin $\left(\mathrm{N}_{\mathrm{MH}}=\mathrm{V}_{\mathrm{OH}}-\mathrm{V}_{\mathrm{IH}}\right)$ is $1.67 \mathrm{~V}$. 


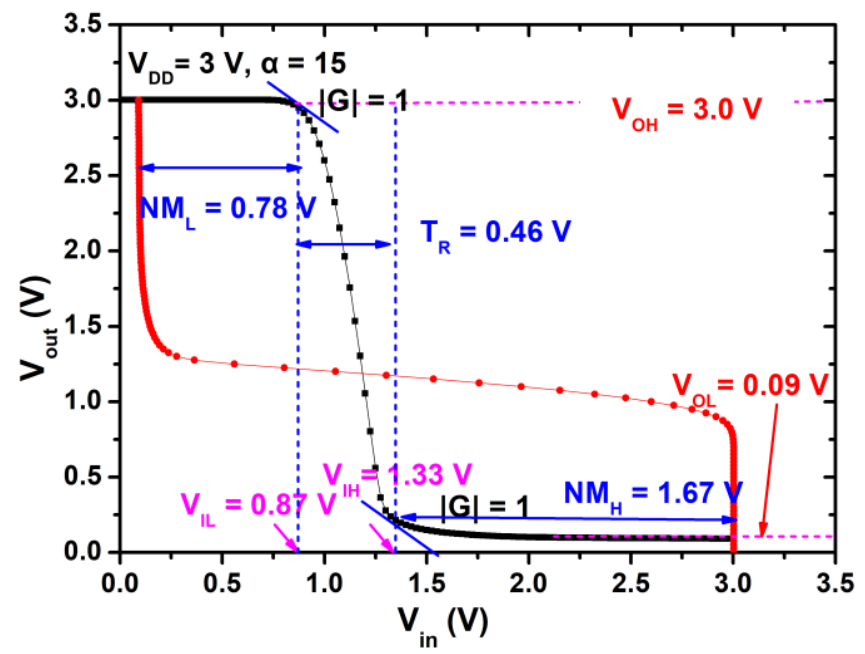

Figure 5. Static voltage transfer characteristics of the inverter with $\alpha=15$ measured at supply voltage $\mathrm{V}_{\mathrm{DD}}=3 \mathrm{~V}$.

Figure 6 shows the measured voltage transfer characteristics for E/D-mode GaN inverters of different $\alpha$ with $\mathrm{V}_{\mathrm{DD}}=3 \mathrm{~V}$. Table 1 summarizes the parameters of the inverters.

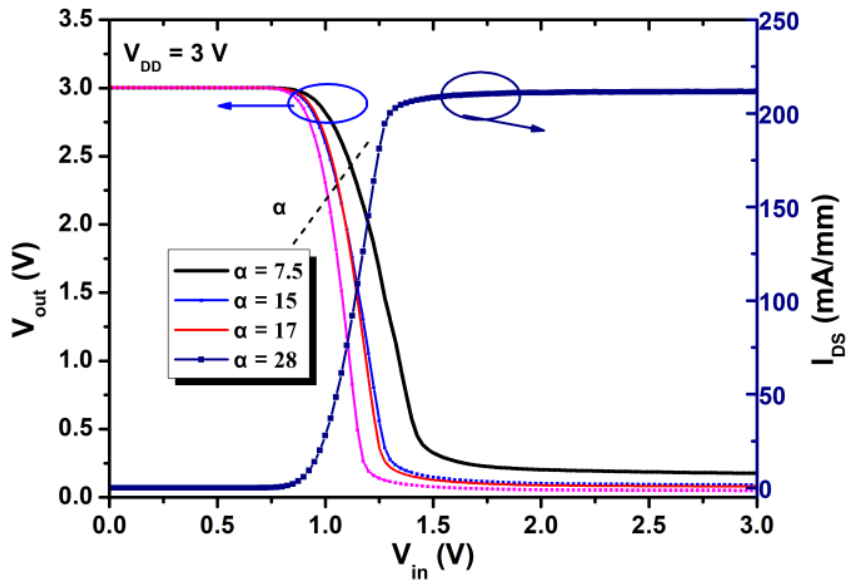

Figure 6. The static voltage transfer curve of the inverter with different $\alpha$ at $V_{D D}=3 \mathrm{~V}$.

Table 1. Noise margins for inverters with different $\alpha$.

\begin{tabular}{cccccccc}
\hline $\boldsymbol{\alpha}$ & $\mathbf{V}_{\mathbf{O H}}(\mathbf{V})$ & $\mathbf{V}_{\mathbf{O L}}(\mathbf{V})$ & Output Swing $(\mathbf{V})$ & $\mathbf{V}_{\mathbf{T H}}(\mathbf{V})$ & $\mathbf{G}$ & $\mathbf{N}_{\mathbf{M L}}(\mathbf{V})$ & $\mathbf{N}_{\mathbf{M H}}(\mathbf{V})$ \\
\hline 7.5 & 3.0 & 0.17 & 2.83 & 1.30 & 5.5 & 0.76 & 1.53 \\
15 & 3.0 & 0.09 & 2.91 & 1.18 & 6.8 & 0.78 & 1.67 \\
17 & 3.0 & 0.07 & 2.93 & 1.17 & 6.9 & 0.79 & 1.70 \\
28 & 3.0 & 0.05 & 2.95 & 1.11 & 8.3 & 0.80 & 1.80 \\
\hline
\end{tabular}

As shown in Figure 6, the $V_{\mathrm{OH}}$ is $3.0 \mathrm{~V}$ with all $\alpha$, indicating that the E-mode HEMTs are well switched off. The $\mathrm{V}_{\mathrm{OL}}$ is decreasing with larger $\alpha$ and it is only $0.05 \mathrm{~V}$ with $\alpha=28$. The $\mathrm{V}_{\mathrm{OL}}$ can be described as below.

$$
\mathrm{V}_{\mathrm{OL}}=\frac{R_{E}}{R_{E}+R_{D}} \mathrm{~V}_{D D}
$$

When the values of $\alpha$ increase, the $R_{E}$ becomes smaller and equivalent resistance of E-mode transistor is much smaller than the overall resistance of the circuit, and the $\mathrm{V}_{\mathrm{OL}}$ decreases. Also, larger values of $\alpha$ result in sharper transitions and smaller transition 
voltage. As a result, the output swing increases from $2.83 \mathrm{~V}$ to $2.95 \mathrm{~V}$. As $\alpha$ increases from 7.5 to 28 , the threshold of the inverter decreases from $1.30 \mathrm{~V}$ to $1.11 \mathrm{~V}$, and the DC voltage gain $(\mathrm{G})$ in the linear region increases from 5.5 to 8.3. Table 1 lists the measured values of static noise margins, as well as $\mathrm{V}_{\mathrm{OH}}, \mathrm{V}_{\mathrm{OL}}$, output logic swing, $\mathrm{V}_{\mathrm{TH}}$, inverter, and $\mathrm{G}$. Both $\mathrm{N}_{M L}$ and $\mathrm{N}_{M H}$ are improved as $\alpha$ increases. However, on the other hand, as the active load D-mode HEMT is kept unchanged and the gate length of the E-mode is kept as a constant, larger $\alpha$ will increase the capacitance of the E-mode HEMT, and this will decrease the speed of the inverter.

The static voltage transfer curves of the inverter with $\alpha=15$ were measured at different supply voltages and are plotted in Figure 7. The circuit performance parameters are listed in Table 2. When supply voltage increases, all the parameters of the E/D inverter increase accordingly. This means that the increase of supply voltage improves the static performance of the E/D inverter. Furthermore, magnitude of increase for the high noise margin is larger than that of the low noise.

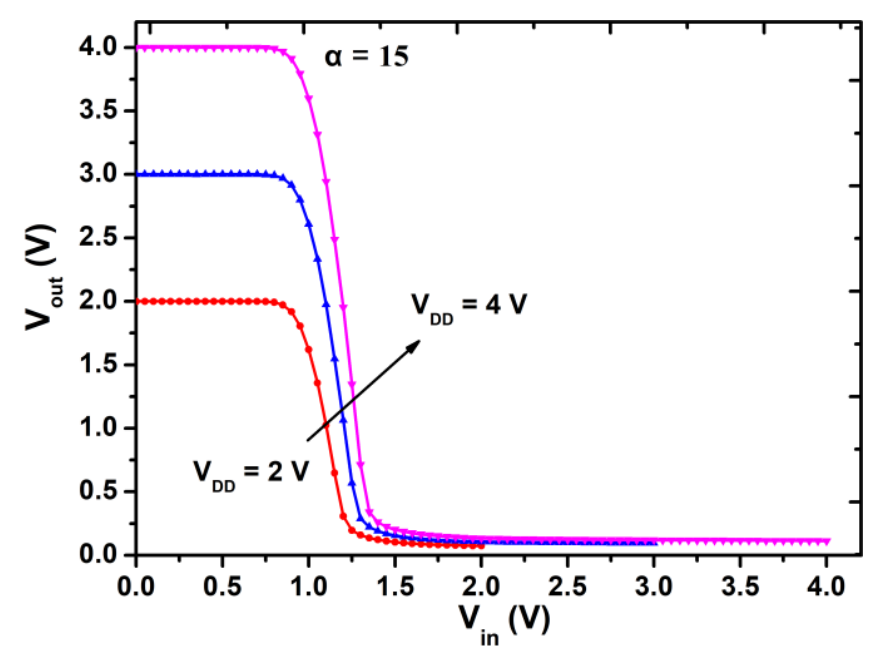

Figure 7. The static voltage transfer characteristics of the inverter with $\alpha=15$ measured at supply voltage $\mathrm{V}_{\mathrm{DD}}=2,3,4 \mathrm{~V}$.

Table 2. Noise margins for inverters with different $V_{\mathrm{DD}}$ with $\alpha=15$.

\begin{tabular}{cccccccc}
\hline$V_{\mathbf{D D}}(\mathrm{V})$ & $V_{\mathrm{OH}}(\mathrm{V})$ & $V_{\mathrm{OL}}(\mathrm{V})$ & Output Swing $(\mathrm{V})$ & $V_{\mathrm{TH}}(\mathrm{V})$ & $G$ & $N_{\mathrm{ML}}(\mathrm{V})$ & $N_{\mathrm{MH}}(\mathrm{V})$ \\
\hline 2 & 2.0 & 0.07 & 1.93 & 1.08 & 5.2 & 0.77 & 0.75 \\
3 & 3.0 & 0.09 & 2.91 & 1.18 & 6.8 & 0.78 & 1.63 \\
4 & 4.0 & 0.11 & 3.89 & 1.25 & 7.1 & 0.80 & 2.59 \\
\hline
\end{tabular}

High-temperature performance of the inverter circuits is characterized by varying the temperature from $25^{\circ} \mathrm{C}$ to $200{ }^{\circ} \mathrm{C}$ in Figure 8. The insert figure plots the DC output and transfer characteristics of the inverter at $200^{\circ} \mathrm{C}$. Table 3 summarizes the parameters of the inverters at different temperature with $\mathrm{V}_{\mathrm{DD}}=3 \mathrm{~V}$ and $\alpha=15$.

Table 3. Noise margins for inverters at different temperature.

\begin{tabular}{cccccccc}
\hline $\mathbf{T}\left({ }^{\circ} \mathbf{C}\right)$ & $\mathbf{V}_{\mathbf{O H}}(\mathbf{V})$ & $\mathbf{V}_{\mathbf{O L}}(\mathbf{V})$ & Output Swing $(\mathbf{V})$ & $\mathbf{V}_{\mathbf{T H}}(\mathbf{V})$ & $\mathbf{G}$ & $\mathbf{N}_{\mathbf{M L}}(\mathbf{V})$ & $\mathbf{N}_{\mathbf{M H}}(\mathbf{V})$ \\
\hline$R T$ & 3.0 & 0.09 & 2.91 & 1.18 & 6.8 & 0.78 & 1.67 \\
100 & 3.0 & 0.09 & 2.91 & 1.21 & 5.8 & 0.80 & 1.63 \\
150 & 3.0 & 0.12 & 2.88 & 1.17 & 6.9 & 0.67 & 1.58 \\
200 & 3.0 & 0.11 & 2.89 & 1.09 & 6.8 & 0.68 & 1.72 \\
\hline
\end{tabular}

As shown in the insert figure in Figure 8, the inverter functions well at $\mathrm{V}_{\mathrm{DD}}$ of $3 \mathrm{~V}$ in terms of $\mathrm{V}_{\mathrm{OH}}, \mathrm{V}_{\mathrm{OL}}$, logic voltage swing, $\mathrm{V}_{\mathrm{TH}}, \mathrm{N}_{M \mathrm{~L}}$ and $\mathrm{N}_{\mathrm{MH}}$, and they are $3 \mathrm{~V}, 0.11 \mathrm{~V}, 2.89 \mathrm{~V}$, $1.09 \mathrm{~V}, 0.68 \mathrm{~V}$ and $1.72 \mathrm{~V}$, respectively. It should be noted that the $\mathrm{V}_{\mathrm{OH}}$ of $3 \mathrm{~V}$ and $\mathrm{V}_{\mathrm{OL}}$ of 
$0.11 \mathrm{~V}$ suggest that the inverter can successfully turn-on and turn-off the E-mode device even at $200{ }^{\circ} \mathrm{C}$.Small variations of the inverter from RT to $200^{\circ} \mathrm{C}$ can be ascribed to two factors. Firstly, the E-mode HEMT exhibits with a small variation of about $0.1 \mathrm{~V}$ at RT and $200{ }^{\circ} \mathrm{C}$. Similar behavior of the threshold voltage was also demonstrated in [10]. Secondly, the low off-state leakage of the E-mode HEMT up to $200{ }^{\circ} \mathrm{C}$ is critical for the inverter to obtain a high level $\mathrm{V}_{\mathrm{OH}}$ and low level $\mathrm{V}_{\mathrm{OL}}$ at high temperature, making it possible to obtain a large logic voltage swing and noise margins without obvious variations for the inverter in such temperature range. The two factors work together to make this E/D-mode inverter capable of functioning properly up to $200{ }^{\circ} \mathrm{C}$ and exhibit small variations in terms of logic voltage swing, $\mathrm{V}_{\mathrm{TH}}, \mathrm{N}_{M \mathrm{~L}}$ and $\mathrm{N}_{M H}$ from RT to $200^{\circ} \mathrm{C}$.

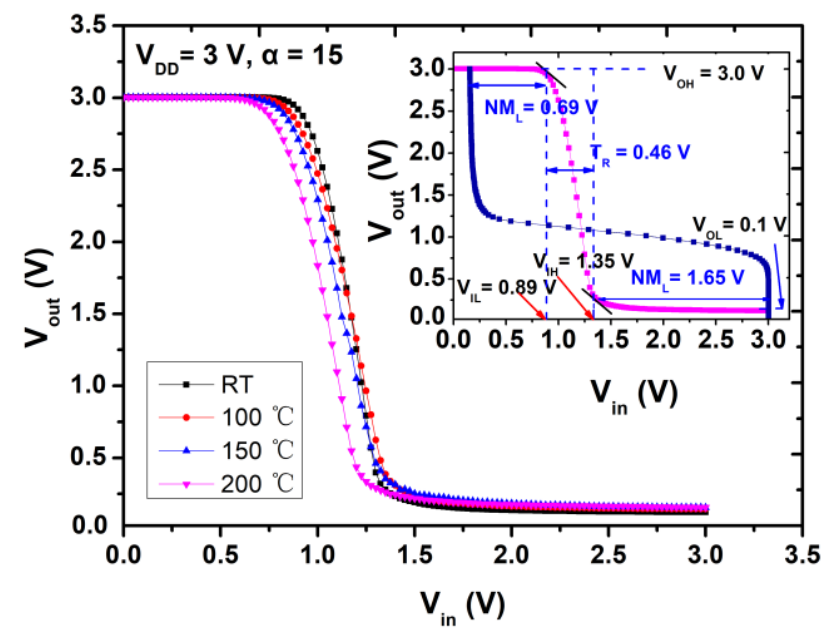

Figure 8. The static voltage transfer curve of the inverter at different temperature from $25{ }^{\circ} \mathrm{C}$ to $200{ }^{\circ} \mathrm{C}$ with $\mathrm{V}_{\mathrm{DD}}=3 \mathrm{~V}$; insert: DC output and transfer characteristics of the inverter at $200^{\circ} \mathrm{C}$.

Figure 9 shows the transient output waveforms of the fabricated E/D-mode GaN inverters of different $\alpha$ with input of $20 \mathrm{kHz}$ square wave from 0 to $3 \mathrm{~V}$, and an edge time of $10 \mathrm{~ns}$. As $\alpha$ increases from 7.5 to 28 , the rising edge time of the output signal increases from $1.05 \mu \mathrm{s}$ to $1.66 \mu \mathrm{s}$. The data are much smaller than that in the literature [15] and this may result from the excellent characteristics of the $\mathrm{p}-\mathrm{GaN}$ gate E-mode HEMT. Generally, an inverter with smaller $\alpha$ may have poorer DC performance, but it will have better performance for dynamic characteristics. Designers will trade-off between the static and dynamic performance and select a proper $\alpha$.

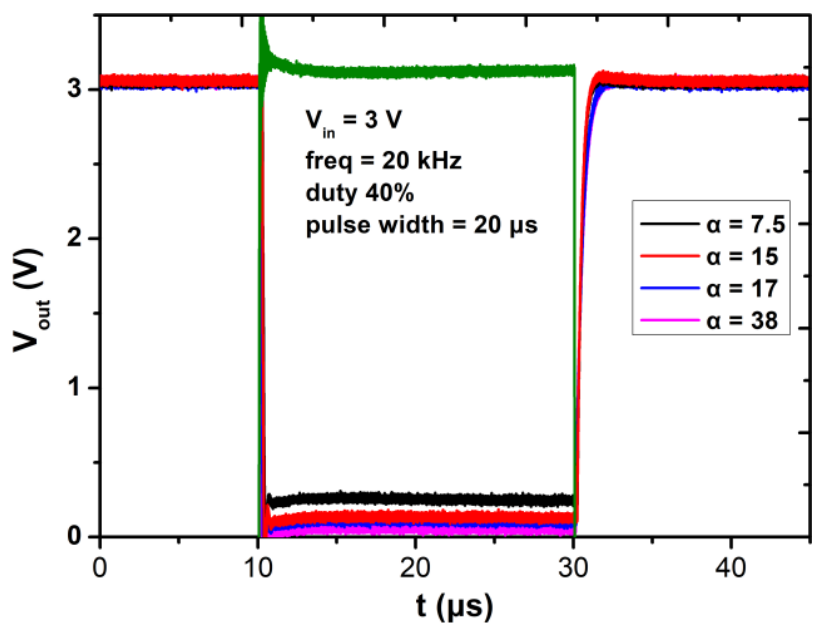

Figure 9. The transient output waveforms with input of $20 \mathrm{kHz}$ square wave from 0 to $3 \mathrm{~V}$ with different $\alpha$. 


\section{Conclusions}

In this paper, $\mathrm{AlGaN} / \mathrm{GaN}$ E/D-mode HEMTs and inverters were successfully fabricated on a 150-mm Si wafer based on p-GaN gate technology. The fabricated E/D-mode devices and inverters were characterized and analyzed. The inverter shows large input logic swing voltage, high noise margin and small transition voltage region. Excellent characteristics were displayed at high temperature, and small variations at high temperature in terms of logic voltage. The inverters also demonstrate small rising edge time of the output signal, and the results show great potential for GaN smart power ICs.

Author Contributions: Data curation, J.-P.X.; Formal analysis, D.-F.L. and J.-C.Z.; Investigation, L.Z. and Z.C.; Project administration, Y.-J.A. and Y.Z.; Writing—original draft, L.-F.J.; Writing—review and editing, Y.Z. All authors have read and agreed to the published version of the manuscript.

Funding: This research was funded by by National Key Research and Development Program of China under Grant No. 2017YFB0402903, and the Science Challenge Project under Grant TZ2018003, and the National Natural Science Foundation of China under Grant 61874114, 61674143 and 61974137.

Data Availability Statement: The data presented in this paper is available with request from the corresponding author.

Acknowledgments: We would like to thank Yongjian Lu, Zhenyu Yuan and Nian Liang for support of the fabrication process and thank Qiyang Ma, Zhixiu Cheng and Chenyi Lin for the transient measurement.

Conflicts of Interest: The authors declare no conflict of interest.

\section{References}

1. Chen, K.J.; Häberlen, O.; Lidow, A.; Tsai, C.L.; Ueda, T.; Uemoto, Y.; Wu, Y. GaN-on-Si Power Technology Devices and Applications. IEEE Trans. Electron Devices 2017, 64, 779-795. [CrossRef]

2. Lidow, A. Gallium Nitride Integration: Going Where Silicon Power Can't Go. IEEE Power Electron. Mag. 2018, 5, 70-72. [CrossRef]

3. Wong, K.; Kwan, M.H.; Yao, F.W.; Tsai, M.W.; Lin, Y.; Chang, Y.; Chen, P.; Su, R.; Yu, J.; Yang, F.; et al. A next generation CMOS-compatible GaN-on-Si transistors for high efficiency energy systems. In Proceedings of the 2015 IEEE International Electron Devices Meeting (IEDM), Washington, DC, USA, 7-9 December 2015; pp. 229-232.

4. Frolov, F.; Lettl, J. Design of High Efficiency and High Frequency GaN DC/DC Converter. In Proceedings of the 2020 21st International Scientific Conference on Electric Power Engineering (EPE), Prague, Czech Republic, 19-21 October 2020; pp. 1-4.

5. Wang, B.; Riva, M.; Bakos, J.D.; Monti, A. Integrated circuit implementation for a GaN HFET driver circuit. IEEE Trans. Ind. Appl. 2010, 46, 2056-2067. [CrossRef]

6. Zhu, M.; Matioli, E. Monolithic integration of GaN-based NMOS digital logic gate circuits with E-mode power GaN MOSHEMTs. In Proceedings of the 2018 IEEE 30th International Symposium on Power Semiconductor Devices and ICs (ISPSD), Chicago, IL, USA, 13-17 May 2018; pp. 236-239.

7. Micovic, M.; Tsen, T.; Hu, M.; Hashimoto, P.; Willadsen, P.J.; Milosavljevic, I.; Schmitz, A.; Antcliffe, M.; Zhender, D.; Moon, J.S.; et al. GaN enhancement/depletion-mode FET logic for mixed signal applications. IEEE Electron Device Lett. 2014, 35, 336-338. [CrossRef]

8. Xu, Z.; Wang, J.; Cai, Y.; Liu, J.; Yang, Z.; Li, X.; Wang, M.; Yu, M.; Xie, B.; Wu, W.G.; et al. High Temperature Characteristics of GaN-Based Inverter Integrated with Enhancement-Mode (E-Mode) MOSFET and Depletion-Mode (D-Mode) HEMT. IEEE Electron Device Lett. 2014, 35, 33-35. [CrossRef]

9. Tang, Y.; Saunier, P.; Wang, R.; Ketterson, A.; Gao, X.; Guo, S.; Snider, G.; Jena, D.; Xing, H.; Fay, P. High-performance monolithically-integrated E/D mode InAlN/AlN/GaN HEMTs for mixed-signal applications. In Proceedings of the 2010 International Electron Devices Meeting, San Francisco, CA, USA, 6-8 December 2010; pp. 684-687.

10. Cai, Y.; Cheng, Z.; Tang, W.C.; Lau, K.M.; Chen, K.J. Monolithically Integrated Enhancement/Depletion-Mode AlGaN/GaN HEMT Inverters and Ring Oscillators Using $\mathrm{CF}_{4}$ Plasma Treatment. IEEE Trans. Electron Devices 2006, 53, 2223-2230. [CrossRef]

11. Posthuma, N.E.; You, S.; Stoffels, S.; Wellekens, D.; Liang, H.; Zhao, M.; De Jaeger, B.; Geens, K.; Ronchi, N.; Decoutere, S.; et al. An industry-ready $200 \mathrm{~mm}$ p-GaN E-mode GaN-on-Si power technology. In Proceedings of the 2018 IEEE 30th International Symposium on Power Semiconductor Devices and ICs (ISPSD), Chicago, IL, USA, 13-17 May 2018; pp. $284-287$.

12. Zhou, D.C.; Chiu, H.C.; Zhang, J.; Wong, R.K.; Zhao, T.; Zhang, F.; Zhang, M.; Zou, Y.; Chen, L. A Massive Adoption Ready 200mm 40V-650V E-mode GaN-on-Si Power HEMTs Technology. In Proceedings of the 2020 IEEE Applied Power Electronics Conference and Exposition (APEC), New Orleans, LA, USA, 15-19 March 2020; pp. 636-639.

13. Tang, G.; Kwan, A.M.; Wong, R.K.; Lei, J.; Su, R.Y.; Yao, F.W.; Lin, Y.M.; Yu, J.L.; Tsai, T.; Tuan, H.C.; et al. Digital integrated circuits on an e-mode gan power hemt platform. IEEE Electron Device Lett. 2017, 38, 1282-1285. [CrossRef] 
14. Moench, S.; Reiner, R.; Waltereit, P.; Müller, S.; Quay, R.; Ambacher, O.; Kallfass, I. A 600V p-GaN Gate HEMT with Intrinsic Freewheeling Schottky-Diode in a GaN Power IC with Bootstrapped Driver and Sensors. In Proceedings of the 202032 nd International Symposium on Power Semiconductor Devices and ICs (ISPSD), Vienna, Austria, 13-18 September 2020; pp. 254-257.

15. Sun, R.; Liang, Y.C.; Yeo, Y.C.; Zhao, C.; Chen, W.; Zhang, B. All-gan power integration: Devices to functional subcircuits and converter ics. IEEE J. Emerg. Sel. Top. Power Electron. 2020, 8, 31-41. [CrossRef] 